\title{
Rising trend of proximal femoral nail in therapy of Extracapsular Hip Fractures
}

\author{
Ganvir $\mathrm{A}^{1}$, Sonkar $\mathrm{D}^{2}$, Shukla $\mathbf{J}^{3}$, Gaur $\mathrm{S}^{4}$ \\ ${ }^{1}$ Dr.Ajit Ganvir, Assistant Professor, Department of Orthopaedics, ${ }^{2}$ Dr. Deependra Sonkar, Assistant Professor, Department \\ of Orthopaedics, ${ }^{3}$ Prof. Dr. Jiten Shukla, Professor of Orthopaedics, Department of Orthopaedics, ${ }^{4}$ Prof. Dr. Sanjeev Gaur, \\ Professor and Head, Department of Orthopaedics. All are affiliated to Gandhi Medical College, Bhopal, MP, India.
}

Address for correspondence: Dr Ajit Ganvir, Email id: ajitmedico@yahoo.com,

\begin{abstract}
Introduction: Fracture distal to the capsular attachment i.e. pertrochanteric area of hip including intertrochanteric and sub trochanteric region called as extracapsular hip fractures. Management of these fractures is big challenge in acute trauma. Unstable Extracapsular hip fractures accounts for $2 \%$ of all hip fractures. Dynamic hip screw (DHS) has some surgical drawback in unstable extra capsular hip fractures leading to more usage of proximal femoral nail (PFN). Aim of of Study: This study is undertaken to assess the changing patterns of Dynamic hip screw and Proximal femoral nail in extra capsular hip fractures. Materials and Methods: This is a retrospective study from 2008 to 2014. The study included 786 patients (Mean age 66.2 years) who underwent Dynamic hip screw and Proximal femoral nail fixation for extracapsular hip fractures. Out of 786 patients, 508 patients had DHS fixation and 278 patients had PFN fixation. Results: This study evaluated early complications and technical failures of both methods. Fracture classification used was AO type and patients were divided into two methods of fixation. Data analysis showed dramatically rising trend of PFN. Conclusion: We have concluded that PFN was used aggressively in the last 3 years which may be due to the changing behavior of fracture pattern. It may be intrinsic attraction to new surgical techniques with the younger orthopaedic surgeons.
\end{abstract}

Key words: Dynamic Hip Screw, Proximal Femoral Nail, Extracapsular Hip Fracture, Trend.

\section{Introduction}

Fractures which are located distal to the capsular attachment of hip are called as extracapsular hip fracture. The incidence of extracapsular hip fracture has been estimated to be more than 250000 patients each year in the united states, with the reported mortality ranging from $15-20 \%[1,2]$. The incidence of extracapsular hip fracture has increased significantly during recent years due to the advancing age of the world's population [3]. The reverse oblique trochanteric fractures of proximal part of femur is a distinct fracture pattern which is mechanically different and accounts for $2 \%$ of all the hip fracture and $5 \%$ of all the intertrochanteric and subtrochanteric fracture[4]. Most frequently these fractures are seen in two patients population, namely older osteopenic patients with a low energy trauma and younger patients with high energy trauma[5,6,7,]. With these fractures old patients withstand badly their immobilization in bed \& they are threatened with hypostatic pneumonia, catheter sepsis, cardiorespiratory failure, and decubitus. Moreover, nursing care is also aggravated by psychological changes. All the circumstances mentioned above require using an

Manuscript received: $16^{\text {th }}$ Apr 2015

Reviewed: $22^{\text {th }}$ Apr 2015

Author Corrected: $16^{\text {th }}$ May 2015

Accepted for Publication: $31^{\text {st }}$ May 2015

International Journal of Medical Research and Review urgent surgical solution for a vital indication because early rehabilitation and mobilization of the patient scan be possible in this way. The sliding hip screw and side plate have for decades been the implant of choice in the management of extracapsular hip fractures [8].Cutting out of the sliding hip screw, excessive medialisation of the distal fragment (in unstable fracture) and collapse upon weight bearing are major concern $[9,10]$. To overcome these problems intramedullary device has been more used, one of them is proximal femoral nail (PFN) which has been used since few years in our institute.

Classification [11, 12]: Based on the AO classification of fractures, these fractures ranges from simple intertrochanteric to multifragmental fractures of trochanteric region and may involve:

- Fracture of neck of femur/intracapsular/mediocervical column fracture (31B2)

- Fracture intertrochanter/extracapsular/laterocervical column fracture (31A 1 to $31 \mathrm{~A} 3$ )

- Pertrochanteric fracture

- Isolated fracture of trochanter

- Subtrochanter fracture i.e. fracture in the zone of transition between the proximal end and the femur diaphysis (about $5 \mathrm{~cm}$ distal to lesser trochanter).

Available online at: www.ijmrr.in 424 | P a g e 


\section{Material and Methods}

Now a days, so many methods of surgical solution of fracture of the proximal femur have been available. When choosing a certain method, the type of the fracture, age and biological condition of the patient, the degree of osteoporosis, the state of the hip joint, last but not least, the period elapsed from the injury to the day of surgery of patient must be taken into consideration. In extracapsular fractures, two methods best meet the requirements of stable osteosynthesis at present: DHS and PFN.

In multifragmental fractures treated with DHS, medialisation can be prevented by applying a trochanteric stabilizing splint. Angle and T-shaped splints are less reliable as they fail in such types of fractures where a medial support is missing [13].

Our retrospective study consisted of 786 patients with extracapsular hip fractures, from 2008 to 2014 in Gandhi

\section{Research Article}

medical college and Hamidia hospital Bhopal. 508 patients were treated with DHS fixation and 278 patients were treated with PFN fixation.

All surgeries were done under spinal anaesthesia, in supine position on traction table, a $\mathrm{C}$ arm was placed between his/her lower limb in the angle of about 45 degree to the operated extremity. Preoperative parentral antibiotics administered $1 \mathrm{hr}$ before surgery [14]. The definitive closed reduction of fracture was completed on a traction table. Those fractures which not reduced by close manipulation, opened limited to achieve satisfactory reduction and hold with bone holding forceps during procedure, then surgical procedure was performed either DHS or PFN fixation. In early postoperative periods complication (systemic and local) and technical failures were noted so observation analysis was done to compare in both method of fixation.

\section{Results}

Table 1: showing distribution of patients and fracture type in study population with pre fracture variable

\begin{tabular}{|l|l|l|l|l|}
\hline & & Total & DHS & PFN \\
\hline \multirow{3}{*}{ Gender } & & $\mathrm{n}=786(\%)$ & $\mathrm{n}=508(\%)$ & $\mathrm{n}=278(\%)$ \\
\hline \multirow{3}{*}{ Injury type } & $\mathrm{F}$ & $575(73.16)$ & $401(78.94)$ & $174(62.59)$ \\
\cline { 2 - 5 } & $\mathrm{M}$ & $211(26.14)$ & $107(21.06)$ & $104(37.41)$ \\
\cline { 2 - 5 } & Low energy & $193(24.55)$ & $126(24.80)$ & $67(24.10)$ \\
\cline { 2 - 5 } AOacture type $[11]$ & High energy & $593(75.45)$ & $382(75.20)$ & $211(75.90)$ \\
\cline { 2 - 5 } & $31 \mathrm{~A} 1$ & $155(19.72)$ & $125(24.61)$ & $30(10.79)$ \\
\cline { 2 - 5 } & $31 \mathrm{~A} 2$ & $309(39.31)$ & $161(31.69)$ & $148(53.24)$ \\
\cline { 2 - 5 } & $31 \mathrm{~A} 3$ & $286(36.39)$ & $200(39.37)$ & $86(30.94)$ \\
\cline { 2 - 5 } & $31 \mathrm{~B} 2$ & $36(4.58)$ & $22(4.33)$ & $14(5.04)$ \\
\hline
\end{tabular}

Females were more frequently involved in fractures. According to AO classification [11] there were 155 cases with $31 \mathrm{~A} 1$, 309 cases with 31A2, 286 cases with $31 \mathrm{~A} 3$ and 36 cases were of $31 \mathrm{~B} 2$ fracture type.

Table 2: Year wise opertated man and female in bothe methods of fixation.

\begin{tabular}{|l|l|l|l|l|l|}
\hline Year & DHS & \multicolumn{2}{l|}{ PFN } & Total \\
\hline & Male & Female & Male & Female & \\
\hline 2008 & 15 & 49 & 14 & 06 & 84 \\
\hline 2009 & 15 & 47 & 13 & 11 & 86 \\
\hline 2010 & 17 & 55 & 12 & 16 & 100 \\
\hline 2011 & 14 & 55 & 14 & 23 & 106 \\
\hline 2012 & 15 & 58 & 19 & 28 & 120 \\
\hline 2013 & 13 & 72 & 14 & 45 & 144 \\
\hline 2014 & 18 & 65 & 18 & 45 & 146 \\
\hline Total & 107 & 401 & 104 & 174 & 786 \\
\hline
\end{tabular}

From 2008 to 2014, 786 patients with proximal femoral fractures were treated using DHS and PFN. The study consisted of 211 males and 575 females. The average age was 66.2 years (men 64.1 years and women 68.3 years). 


\section{Research Article}

Table 3: Comparison of DHS of PFN for Extracapsular hip fracture each year from 2008 through 2014

\begin{tabular}{|l|l|l|l|}
\hline Year & DHS & PFN & Total \\
\hline 2008 & $64(76.19)$ & $20(23.81)$ & $\mathrm{n}=84$ \\
\hline 2009 & $62(72.10)$ & $24(27.90)$ & $\mathrm{n}=86$ \\
\hline 2010 & $72(72)$ & $28(28)$ & $\mathrm{n}=100$ \\
\hline 2011 & $69(65.10)$ & $37(34.90)$ & $\mathrm{n}=106$ \\
\hline 2012 & $73(60.83)$ & $47(39.17)$ & $\mathrm{n}=120$ \\
\hline 2013 & $85(59.03)$ & $59(40.97)$ & $\mathrm{n}=144$ \\
\hline 2014 & $83(56.85)$ & $63(43.15)$ & $\mathrm{n}=146$ \\
\hline Total & $\mathbf{5 0 8}$ & $\mathbf{2 7 8}$ & $\mathbf{7 8 6}$ \\
\hline
\end{tabular}

Over this period of time a dramatic shift in PFN fixation increased from approximately $24 \%$ in 2008 to $43 \%$ in 2014 with the most dramatic increases being in the last three years and DHS fixation decreased from $76.19 \%$ in 2008 to $56.85 \%$ in 2014 (Table 3)

Table 4: Complication observed in both techniques

\begin{tabular}{|ccc|}
\hline Complications & DHS (508) & PFN (278) \\
\hline A. Systemic (I) Pulm. Embolism. & 0 & 1 \\
\hline (II) Bronchopneumonia & 0 & 2 \\
\hline (III) DVT. & 0 & 1 \\
\hline (I) Hematoma & 2 & 0 \\
\hline (II) Infection & 0 & 3 \\
\hline (III)Delayed wound healing. & 12 & 2 \\
\hline C. Technical Failures & & \\
\hline (I) Breakage of guide wire/drill bit & 0 & 4 \\
\hline (II) Iatrogenic fracture of GT. & 9 & 1 \\
\hline (III) Inappropriate length of central & & \\
\hline Screw or DHS screw & 0 & 2 \\
\hline (IV) Difficulty in proximal locking. & 0 & 6 \\
\hline (V) Difficulty in distal locking & 0 & 1 \\
\hline Total. & 23 \\
\hline Percentage wise & 23 \\
\hline Dut & $4.53 \%$ \\
\hline
\end{tabular}

During the immediate postoperative period 4 patients suffered from systemic and 19 patients from local complication(see table 4). No cases of early fixation failure were recorded in both methods of fixation. Some technical complication observed intraoperatively in both methods of fixation (see table 4). Overall observed (intraoperative technical failure and immediate postoperative)complications rate was higher in PFN that was $8.27 \%$ as compared with DHS which was $4.53 \%$.

Fig. 2 Year wise percentage of DHS and PFN.

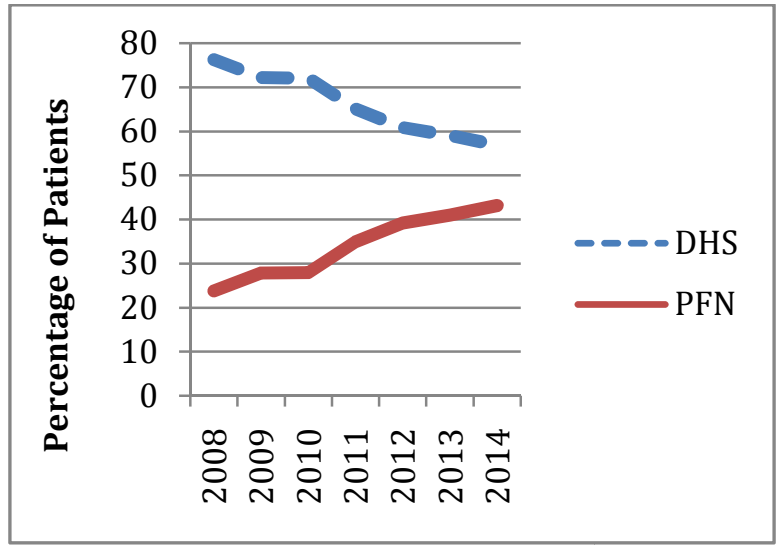

Fig 1: Year wise distribution of patients

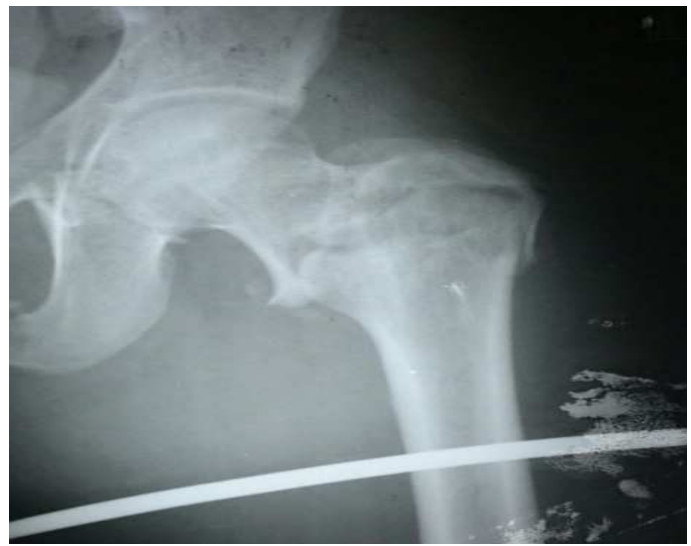

Fig 2: Extracapsular Hip fracture type 31A3 AP view 


\section{Research Article}

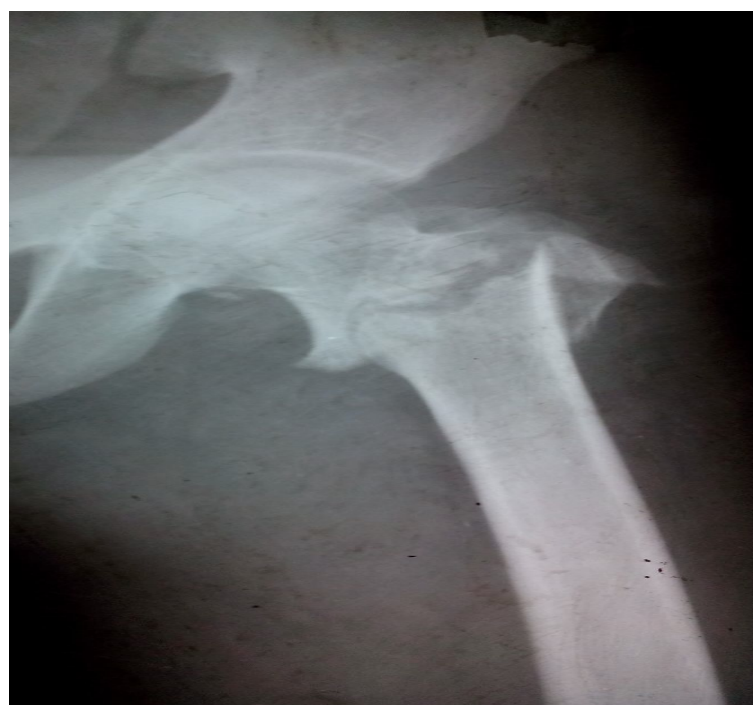

Fig 3: Extracapsular Hip fracture type 31A3 Lateral view

\section{Discussion}

The need for internal fixation and mobilisation of patients with extracapsular hip fractures of the femur is generally accepted, not only to reduce the morbidity \& mortality rates associated with prolonged immobilization, but also to improve the functional results through avoiding malunion and encouraging mobility [10]. DHS initially introduced by Clawson in $1964 \&$ remains the implant of choice because of its favorable results and low rate of nonunion and failure in that decade. It provides centric controlled collapse at the fracture site.

For decades the implant of choice for the treatment of extracapsular hip fracture was a sliding hip screw and side plate was static [8]. Reports of high failure rates especially in the treatment of unstable extracapsular hip fracture due to greater surgical drawback [15] have lead to the introduction of intramedullary nail i.e. Gamma nail (GN).

The use of a DHS has been supported by biomechanical properties [16] which are assumed to be improve the healing of fracture. Intramedullary device such as GN is more rigid than the DHS [17], has greater stability under cyclical loading [18] and greater stiffness under strain[19].

The PFN has been developed as an alternative to the GN, and it seems to be associated with a lower incidence of fracture distal to tip of implant [20].

Simmermacher et al [21] reported an overall technical failure rate of only $4.6 \%$, in a series of 191 fracture ( of which 170 were unstable) and no cases of mechanical failure such as fracture below the tip of nail or bending/breakage of the implant. In our study we found

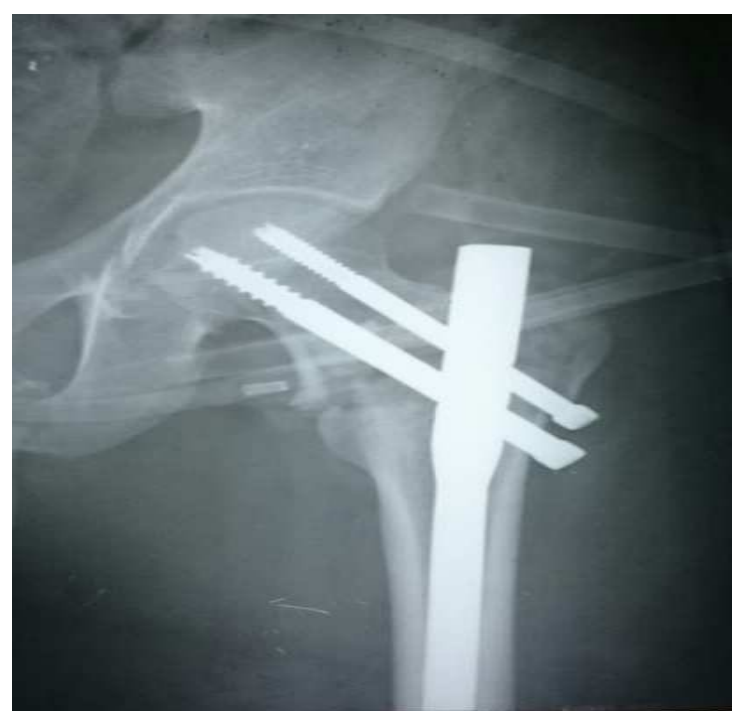

Fig 4: Post Operative X-Ray AP view

$1.77 \%$ technical failure in DHS method and $5 \%$ in PFN method. The most recent study evaluating the use of PFN is from Fogagnolo et al who reported 46 patients with an average rate of intraoperative technical or mechanical complication of $23.41 \%$ [22].

Comparison of technical failure in our study to those in other series isn't easy because an exact definition of failure is absent in most cases. In a study, Perez JV et al suggest early operation and early patient mobilization reduce the risk of fatal pulmonary embolism and the risk of DVT, whereas prolonged bed rest may increases the risk of medical complication such as DVT, pulmonary complication, UTI and skin breakdown [23].

The cephalomedullary Femoral reconstruction nails have gained popularity in recent years to treat extracapsular hip fracture, and shown biomechanical stronger than extramedullary implant [24].

The introduction of PFN into practice has caused an evident qualitative shift in the therapy for extracapsular hip fracture. In accordance with the literature and indication scheme[13,25,26],this method was applied particularly in unstable extracapsular hip fracture.

The scientific evidence, at least in the English language literature, does not support the superiority of intramedullary nail fixation over standard sliding compression hip screw and side plate fixation for the treatment of extracapsular hip fracture [27].

However in our study data shown that PFN has overtaking DHS rapidly among last three years. We do not know for sure why these practices have changed so

Available online at: www.ijmrr.in 427 | P a g e 


\section{Research Article}

dramatically in such a short period in the favour of PFN method. Many surgeon believe that PFN is quicker, easier, more stable and offer improved patient mobility, despite the fact that the English literature does not support these claims. It is possible that there has been change in the nature of fracture type which could be leading cause of raising trend of $\mathrm{PFN}$.

\section{Conclusion}

It is evident from our study that there is rising trend to use PFN in extracapsular hip fractures. It may be that younger orthopaedic surgeons are responding to a change in training and that for some reason residents are currently being trained preferentially in PFN fixation for extracapsular hip fractures. As our institute is a teaching institute in which may be a intrinsic attraction to newer surgical technique. It may be changing behavior of fracture pattern to lead more uses of PFN for extracapsular hip fracture. Younger orthopedic surgeon may be under certain pressure to offer new technique in a medical field that is constantly searching for the latest in technology. It may be that there is no much harm to use PFN even in stable extracapsular hip fracture. Recently there is in an inclination towards minimally invasive surgeries which can be another factor for raising trend of PFN. The author still feels that a judicious use of newer technology is preferable before discarding older stabilized method.

\section{Abbreviations}

PFN: Proximal Femoral Nail, DHS: Dynamic Hip screw, AO: Arbeitgemeinschaft fur Osteosynthesefragen, DVT: Deep vein Thrombosis, GT: Greater Trochanter, GN: Gamma Nail, UTI: Urinary Tract Infection.

Funding: Nil, Conflict of interest: None initiated. Permission from IRB: Yes

\section{References}

1. Cummings SR, Kelsey JL, Nevitt MC, O’Dowd KJ. Epidemiology of osteoporosis and osteoporotic fractures, Epidemiol Rev.1985;7:178-208.

2. Cummings SR, Rubin SM, Black D. The future of hip fractures in the United States. Number, Casts, and potential effect of postmenopousal estrogen. ClinOrthopRelat Res.1990;Mar(252):163-6.

3. Gulberg B, Duppe H, Nilsson B (1993) Incidence of Hip fracture in Malmo, Sweden (1950-1991).Bone 14 [Suppl 1]:23-29.
4. Haidukewych GJ, Israel TA, Berry DJ. Reverse obliquity fracture of the intertrochanteric region of the femur. J. Bone Joint Surg Am.2001;83:643-50.

5. Nieves JW, Bilezikian JP, Lane JM, Einhorn TA, Wang Y, Stanbuch M, et al .Fragility fractures of the hip and femur: incidence and patient characteristics. Osteoporosis Int.2010;21(3):399-408[PubMed].

6. Ekstrom W, Nemeth G, Samnegard E, Dalen N, Tidermark J, Quality of life after a subtrochantric fracture: a prospective cohort study on 87 elderly patients .Injury 2009;40(4):371-376[PubMed].

7. Wiss DA, Brien WW. Sub trochanteric fracture of the femur. Results of treatment by interlocking nailing. ClinOrthop Relate Res. 1992; (283): 231- 236[PubMed].

8. Doppelt SH (1980) The sliding compression screw. Today's best answer for stabilization of inter trochanteric hip fractures OrthopClin North Am 11: 507-523.

9. Flores LA, Harrington IJ, Heller M. The stability of inter trochanteric fractures treated with a sliding screwplate. J Bone Joint Surg Br 1990; 72: 37-40.

10. Simpson AH, Varty K, Dodd CA. Sliding hip screw: Modes of failure. Injury1989; 20: 227-31.

11. Hoffman R Haas NP. Femur : proximal. In: Rudei TP, Murphy WM, eds. AO principles of fracture management Stuttgart, etc: Thieme 2000: 441-54.

12. Nuber S, T Schonweiss, A Rutter. Stabilisation of unstable trochanteric femoral fracture. Dynamic hip screw (DHS) with trochanteric stabilsation plate vs proximal femoral nail (PFN). Unfallchirurg. Jan 2003;106(1):39-47.

13. Ruedi TP, Mureny WM. AO principles of fracture management. Stuttgart: Thieme 2001.

14. Tengre and J. Kjellander ; Antibiotic prophylaxis in operation on trochanteric femoral fractures; Scan J Prim health care sep 2002; 20 (3); 188-92.

15. Sadowski C, Lubbeke A, Saudan M et al (2002). Treatment of reverse and transverse intertrochanteric fractures with use of an intramedullary nail or 95 degree screw- plate: a prospective randomized study. J Bone Joint Surg Am 84 A; 372-381. 


\section{Research Article}

16. Rosenblum SF, Zuckerman JD, Kummer FJ, Ram BS. A biomechanical evoluation of the Gamma Nail. J Bone Joint Surg (Br) 1992; 74-B: 352-7.

17. Curtis MJ , Jinnah RH, Wilson V, Cunningham BW. Proximal femoral fractures: a biomechanical study to compare intramedullary or extra medullary fixation. Injury $1994 ; 25$ : 99- 104.

18. Flahiff CM, Nelson CL, Gruenwald JM, Hollis JM. A biomechanical evaluation of an intramedullary fixation device for intertrochanteric fractures. J Trauma 1993; 35: 23-27.

19. Radford PJ, Needoff M, Webb JK. A prospective randomized comparison of the dynamic hip screw and the gamma locking nail. J Bone Joint Surg 1993; 75-B: 789793.

20. Herrera A, Domingo LJ, Calvo A, Martinez A. A comparative study of trochanteric fractures treated with the gamma nail or the proximal femoral nail. IntOrthop2002 ; 26: 365-9.

21. Muller ME, Nazarian S Koch P, SchatzkerJ , editors. The comprehensive classification of fractures of long bones.Springer, Berlin, 1990 pp 120.
22. Fogagnolo F, Kfuri M Jr, Paccola C. Intramedullary fixation of pertrochanteric hip fractures with the short AO- ASIF proximal femoral nail. Arch Orthop Trauma Surg 2004; 124: 31-37.

23. Perez JV, Warwick DJ, Case CP, Bannister GC (1995) Death after proximal femoral fracture- an autopsy study. Injury 26: 237-240.

24. Windoff J, Hollander DA, Hakimi M, Linhart W (2005) Pitfalls and complications in the use of proximal femoral nail. Langenbecks Arch Surg 390 (1): 59-65 Feb Epub 2004 Apr 15.

25. Bartonicek J, Dousa P, Skala- Rosenbaum J, Kostal R. Trochanteric fractures. A current concept review.UrazovaChirurgi 2001; 10.

26. Pajarinen J, Lindahl J, Michelsson O, Savolainen V, Hirvensalo E. Pertrochanteric femoral fractures treated with a dynamic hip screw or a proximal femoral nail. A randomized study comparing postoperative rehabilitation. J Bone Joint Surg 2005; 87 : 76-8.

27. Parker MJ ,Handoll HH, Gamma and other Cephalocondylic intramedullary nails versus extramedullary implants for extracapsular hip fractures in adults. Cochrane Database Syst Rev. 2005; 4: CD 000093.

\section{How to cite this article?}

Ganvir A, Sonkar D, Shukla J, Gaur S. Rising trend of proximal femoral nail in therapy of Extracapsular Hip Fractures. Int J Med Res Rev 2015;3(4):424-429. doi: 10.17511/ijmrr.2015.i4.084. 